\title{
Effects of perioperative radiation treatment on stricture and fistula formation in hypopharyngeal reconstruction: a meta-analysis
}

Jin Yong Shin ${ }^{1,2}$, Sun-Young Lee ${ }^{2,3}$, Si-Gyun Roh ${ }^{1,2}$, Nae-Ho Lee ${ }^{1,2}$

${ }^{1}$ Department of Plastic and Reconstructive Surgery, Jeonbuk National University Medical School, Jeonju; ${ }^{2}$ Research Institute of Clinical Medicine of Jeonbuk National University-Biomedical Research Institute of Jeonbuk National University Hospital, Jeonju; ${ }^{3}$ Department of Radiation Oncology, Jeonbuk National University Medical School, Jeonju, Korea
Hypopharyngeal reconstruction is a surgically challenging procedure, and postoperative management is important due to a high rate of complications following surgery. In particular, stricture and fistula formation is the most common long-term postoperative complication. Through systematic review and meta-analysis of 21 studies, a significant radiation effect of stricture and fistula formation was found in patients who underwent hypopharyngeal reconstruction. The perioperative radiation must be seen as a critical factor for stricture and fistula formation in hypopharyngeal reconstruction.

Keywords: Fistula / Hypopharyngeal cancer / Stricture

\section{INTRODUCTION}

Reconstruction of the hypopharynx due to extensive oncologic surgery is one of the most difficult and challenging procedures for a surgeon. According to advancements in microsurgical techniques, free tissue transfer for reconstruction of the hypopharyngeal defect has become the primary choice of treatment $[1,2]$. Although free flap surgery is a single-stage repair procedure and could minimize any postoperative complications, morbidity after hypopharyngeal reconstruction remains high [3]. In particular, stricture and fistula are the most common and threatening complications $[4,5]$. These local complications can lead to salivary leakage, swallowing problems, and even fatal carotid artery rupture.

For minimizing the occurrence of these local complications such as stricture and fistula, verifying the predisposing factors

Correspondence: Sun-Young Lee

Department of Radiation Oncology, Jeonbuk National University Hospital,

20 Geonji-ro, Deokjin-gu, Jeonju 54907, Korea

E-mail address: jbsylee78@gmail.com affecting the postoperative results has been an important issue in previous studies. Considering the predisposing treatment factors for hypopharyngeal defect is important because the clinician can predict the postoperative results and try to prevent or minimize these complications. Among these treatment options, preoperative and postoperative radiation treatments have been often implicated in stricture and fistula formation [6,7]. However, the radiation factors for such postoperative complications are still controversial, and no definite studies are presently available. Therefore, the establishment of an association between radiation treatment and postoperative complications, such as stricture and fistula formation, would be beneficial for oncologic patients of the hypopharynx.

Through a review of relevant studies, this study aimed to explore the stricture and fistula formation rate after preoperative or postoperative radiation treatment in patients who underwent hypopharyngeal reconstruction and to determine the degree of association between radiation and these complication rates. 


\section{IDENTIFICATION OF RELEVANT STUDIES}

A search for eligible articles using the PubMed, Embase, and Cochrane Library databases for all studies published prior to January 2020 was conducted according to the Preferred Reporting Items for Systematic Reviews and Meta-Analyses checklist [8]. The purpose of the literature search was to verify the effect of perioperative radiation treatment in patients who underwent hypopharyngeal reconstruction. The search terms included "hypopharynx," "pharyngoesophageal," "pharyngolaryngectomy," "pharyngectomy," and "pharyngeal." Only human studies were included, and relevant articles were examined for references to additional eligible studies.

The inclusion criteria were as follows: (1) a full-length article that provided sufficient data to evaluate the treatment results of preoperative or postoperative radiation treatment in patients who underwent hypopharyngeal reconstruction; (2) a brief description of the location of the operation and whether radiation treatment was used; (3) prospective or retrospective trials; (4) a brief explanation of outcome variables (complication rate such as stricture or fistula formation). Studies were excluded if they involved incomplete or interim data; were written in languages other than English; did not contain information regarding the treatment results; were a case report, review article, letter, or communication; or the authors were overlapping.

Fig. 1 shows the flow diagram of how the eligible studies were investigated. The database searches identified 451 publications that potentially met the study criteria. Duplicate 85 records from 451 studies were excluded. The screening process, consisting of a review of titles and abstracts, excluded 210 studies that did not meet the inclusion criteria. A total of 156 full-text articles were reviewed for eligibility. The reasons for study exclusion during the final review were as follows: incomplete data $(\mathrm{n}=114)$, letter $(\mathrm{n}=3)$, and case report $(\mathrm{n}=18)$. The remaining 21 non-randomized studies were included in the final analysis $[1,5,7,9-26]$.

\section{CHARACTERISTICS OF STUDIES INCLUDED IN THE FINAL ANALYSIS}

Among the 21 studies, we identified a total of 675 patients who underwent hypopharyngeal reconstruction and received perioperative radiation treatment. The clinical data and pooled analysis of the enrolled studies are shown in Table 1. In the enrolled studies, the stricture rate associated with preoperative and postoperative radiation treatment was $0 \%$ to $75 \%$. The fistula rate associated with preoperative and postoperative radiation treatment was $0 \%$ to $100 \%$. The mean stricture rate associated with preoperative and postoperative radiation treatment

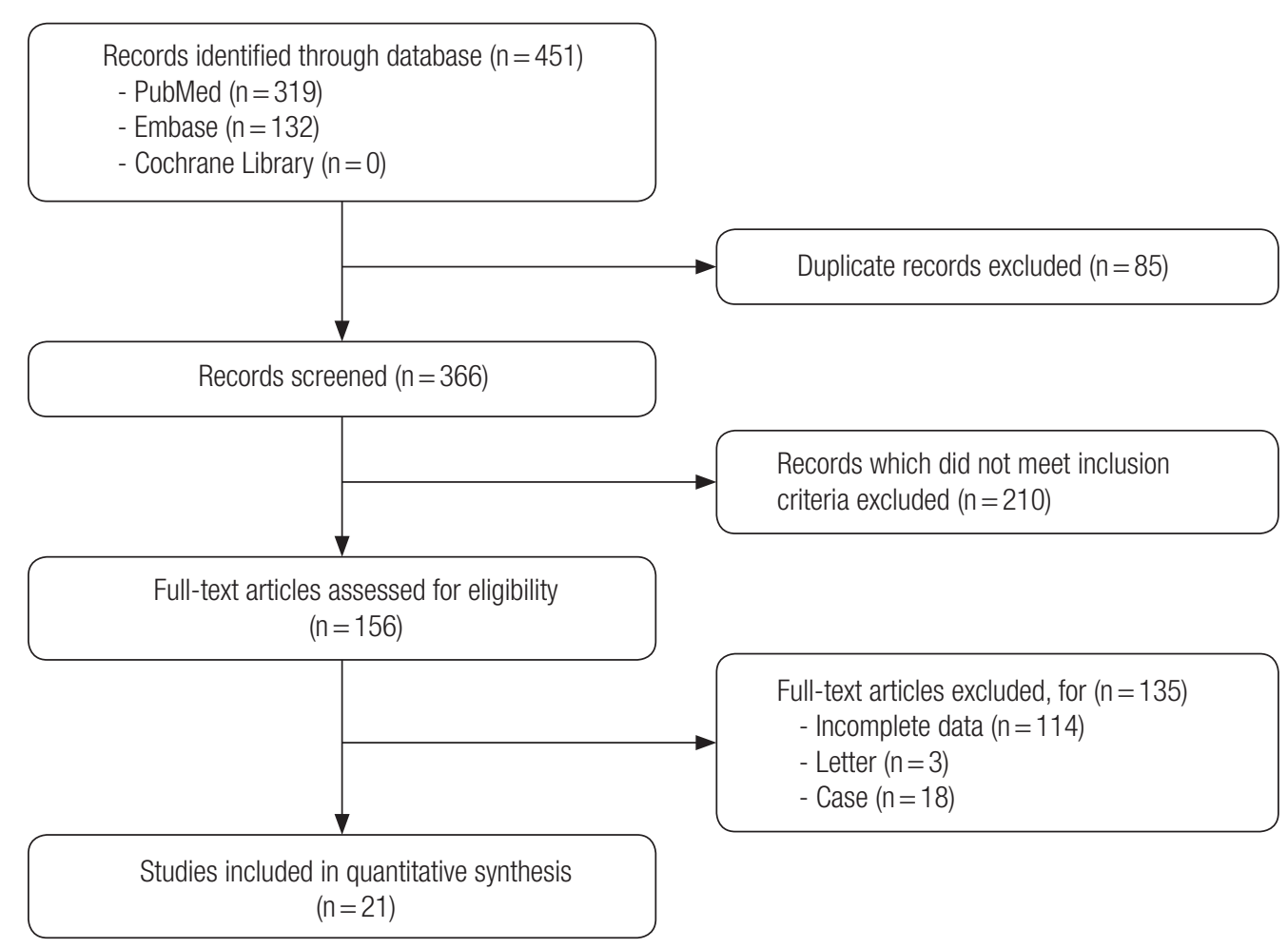

Fig. 1. Flow diagram for identification of relevant studies. 
Table 1. Clinical data of studies included in analysis

\begin{tabular}{|c|c|c|c|c|c|}
\hline Study & No. of patient & Stricture rate (pre-radiation) & Stricture rate (post-radiation) & Fistula rate (pre-radiation) & Fistula rate (post-radiation) \\
\hline Hsueh et al. [9] & 10 & $16.7(1 / 6)$ & $12.5(1 / 8)$ & $0(0 / 6)$ & $12.5(1 / 8)$ \\
\hline Zhang et al. [10] & 23 & & & $22.2(2 / 9)$ & $0(0 / 20)$ \\
\hline Song et al. [11] & 8 & & $0(0 / 5)$ & & $0(0 / 5)$ \\
\hline Andrades et al. [12] & 104 & & & $33.3(19 / 57)$ & $28.3(26 / 92)$ \\
\hline Zhang et al. [13] & 21 & & $23.8(5 / 21)$ & & $4.8(1 / 21)$ \\
\hline Chahine et al. [14] & 15 & $30.0(3 / 10)$ & & $70.0(7 / 10)$ & \\
\hline Scharpf et al. [5] & 28 & $38.9(7 / 18)$ & & $16.7(3 / 18)$ & \\
\hline Amin et al. [15] & 10 & & & $0(0 / 5)$ & \\
\hline Yang et al. [16] & 8 & & & & $16.7(1 / 6)$ \\
\hline Hsiao et al. [17] & 16 & & $18.8(3 / 16)$ & & $6.3(1 / 16)$ \\
\hline Kim et al. [18] & 6 & $0(0 / 1)$ & $0(0 / 5)$ & $100(1 / 1)$ & $20.0(1 / 5)$ \\
\hline Fujiwara et al. [19] & 10 & & $10.0(1 / 10)$ & & \\
\hline Laing et al. [20] & 31 & $18.2(2 / 11)$ & $11.1(2 / 18)$ & $27.3(3 / 11)$ & $11.1(2 / 18)$ \\
\hline Lee et al. [21] & 18 & & & & $8.3(1 / 12)$ \\
\hline Disa et al. [1] & 165 & $5.6(4 / 71)$ & & $12.7(9 / 71)$ & \\
\hline Choi et al. [7] & 100 & & & $10.8(4 / 37)$ & $5.7(2 / 35)$ \\
\hline Ooi et al. [22] & 13 & $23.1(3 / 13)$ & $66.7(2 / 3)$ & $23.1(3 / 13)$ & $0(0 / 3)$ \\
\hline Scaglioni et al. [23] & 14 & & & $23.1(3 / 13)$ & $25.0(1 / 4)$ \\
\hline Parmar et al. [24] & 6 & $0(0 / 1)$ & $75.0(3 / 4)$ & $100(1 / 1)$ & $50.0(2 / 4)$ \\
\hline Zelken et al. [25] & 12 & $30.0(3 / 10)$ & $40.0(2 / 5)$ & $40.0(4 / 10)$ & $40.0(2 / 5)$ \\
\hline Yu et al. [26] & 57 & & $26.3(5 / 19)$ & & \\
\hline
\end{tabular}

Values are presented as percent (number/number). Empty table cells mean the data unextractable, unclear, or unavailable.

was $16.3 \%$ and $21.1 \%$, respectively. The mean fistula rate associated with preoperative and postoperative radiation treatment was $22.5 \%$ and $16.1 \%$, respectively.

\section{THE EFFECTS OF PREOPERATIVE RADIATION TREATMENT}

The stricture rate after preoperative radiation treatment was analyzed in six studies. A meta-analysis yielded a pooled odds ratio for stricture formation of 1.882 (95\% confidence interval [CI], 0.756-4.684; $p=0.174$ ) with low heterogeneity (Fig. 2). The fistula rate after preoperative radiation treatment was analyzed in 13 studies. A meta-analysis yielded a pooled odds ratio for fistula formation of 2.410 (95\% CI, 1.240-4.686; $p=0.010$ ) with low heterogeneity (Fig. 3). Fistula formation was shown to be significantly associated with preoperative radiation treatment.

\section{THE EFFECTS OF POSTOPERATIVE RADIATION TREATMENT}

The stricture rate after postoperative radiation treatment was analyzed in six studies. A meta-analysis yielded a pooled odds ratio for stricture formation of 2.711 (95\% CI, 1.029-7.140; $p=0.044$ ) with low heterogeneity (Fig. 4 ). The fistula rate after postoperative radiation treatment was analyzed in 12 studies. A meta-analysis yielded a pooled odds ratio for fistula formation of 0.811 (95\% CI, $0.400-1.643 ; p=0.560)$ with low heterogeneity (Fig. 5). The stricture formation was shown to be significantly associated with postoperative radiation treatment.

\section{INFLUENCE OF RADIATION TREATMENT}

Additional radiation treatment after extensive dissection of the remnant esophagus makes the vascularity worse, and it can lead to fibrosis and stricture. The effect of radiation on stricture formation is a controversial issue. Some authors suggest that radiation and stricture formation are not related [27,28]. However, other studies identified that there is a significant association of radiation with stricture formation $[29,30]$. Perhaps, stricture induction could be dependent on the dose of radiation. A radiation dose greater than 50-60 Gy may possibly cause stricture formation [31-33]. Typically, the total dose of postoperative radiation was more than $60 \mathrm{~Gy}$ in our enrolled studies [9,11]; therefore, the results of our meta-analysis support a meaningful 
Study name Outcome

$\begin{array}{llcccccc} & & \begin{array}{c}\text { Odds } \\ \text { ratio }\end{array} & \begin{array}{c}\text { Lower } \\ \text { limit }\end{array} & \begin{array}{c}\text { Upper } \\ \text { limit }\end{array} & \text { Z-Value } & \text { p-Value } \\ \text { Chahine. et al } & \text { Stricture formation } & 1.714 & 0.131 & 22.513 & 0.410 & 0.682 \\ \text { Scharpf. et al } & \text { Stricture formation } & 2.545 & 0.414 & 15.652 & 1.008 & 0.313 \\ \text { Laing. et al } & \text { Stricture formation } & 4.222 & 0.337 & 52.902 & 1.117 & 0.264 \\ \text { Disa. et al } & \text { Stricture formation } & 1.811 & 0.392 & 8.362 & 0.761 & 0.447 \\ \text { Parmar. et al } & \text { Stricture formation } & 0.111 & 0.003 & 4.475 & -1.165 & 0.244 \\ \text { Zelken. et al } & \text { Stricture formation } & 2.333 & 0.087 & 62.682 & 0.505 & 0.614 \\ & & 1.882 & 0.756 & 4.684 & 1.360 & 0.174\end{array}$

Heterogeneity: $\chi^{2}=2.774, \mathrm{df}=5(p=0.735) ; \mathrm{I}^{2}=00.000 \%$

Test for overall effect: $Z=1.360(p=0.174)$
Statistics for each study

Odds ratio and $95 \% \mathrm{Cl}$

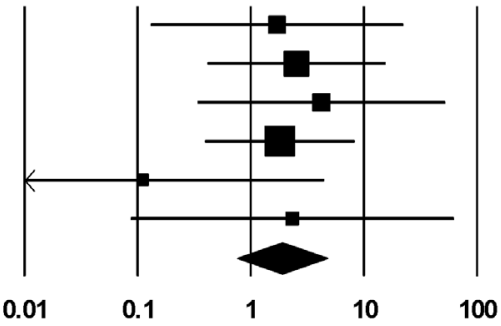

No radiation

Fig. 2. Forest plot of the stricture formation rate associated with preoperative radiation. The diamond indicates the summary estimate of the pooled studies. CI, confidence interval.

\begin{tabular}{|c|c|c|c|c|c|c|}
\hline \multirow[t]{2}{*}{ Study name } & \multirow[t]{2}{*}{ Outcome } & \multirow[b]{2}{*}{$\begin{array}{c}\text { Odds } \\
\text { ratio }\end{array}$} & \multicolumn{3}{|c|}{ Statistics for each study } & \multirow[b]{2}{*}{ p-Value } \\
\hline & & & $\begin{array}{l}\text { Lower } \\
\text { limit }\end{array}$ & $\begin{array}{l}\text { Upper } \\
\text { limit }\end{array}$ & Z-Value & \\
\hline Hsueh. et al & Fistula & 0.179 & 0.006 & 5.678 & -0.975 & \\
\hline Zhang. et al & Fistula & 9.667 & 0.409 & 228.247 & 1.406 & \\
\hline Andrades. et al & Fistula & 1.636 & 0.685 & 3.911 & 1.108 & \\
\hline Chahine. et al & Fistula & 23.571 & 0.999 & 556.078 & 1.959 & \\
\hline Scharpf. et al & Fistula & 0.800 & 0.110 & 5.819 & -0.220 & \\
\hline Amin. et al & Fistula & 0.127 & 0.005 & 3.517 & -1.217 & \\
\hline Kim. et al & Fistula & 9.000 & 0.223 & 362.480 & 1.165 & \\
\hline Laing. et al & Fistula & 16.882 & 0.784 & 363.376 & 1.805 & \\
\hline Disa. et al & Fistula & 6.677 & 1.395 & 31.957 & 2.377 & \\
\hline Choi. et al & Fistula & 2.424 & 0.511 & 11.491 & 1.115 & \\
\hline Scaglioni. et al & Fistula & 1.000 & 0.033 & 30.618 & 0.000 & \\
\hline Parmar. et al & Fistula & 4.200 & 0.116 & 151.970 & 0.784 & \\
\hline Zelken. et al & Fistula & 3.462 & 0.132 & 90.678 & 0.745 & \\
\hline & & 2.410 & 1.240 & 4.686 & 2.593 & \\
\hline
\end{tabular}

Heterogeneity: $\chi^{2}=13.888, \mathrm{df}=12(p=0.308) ; \mathrm{I}^{2}=13.592 \%$ Test for overall effect: $Z=2.593(p=0.010)$

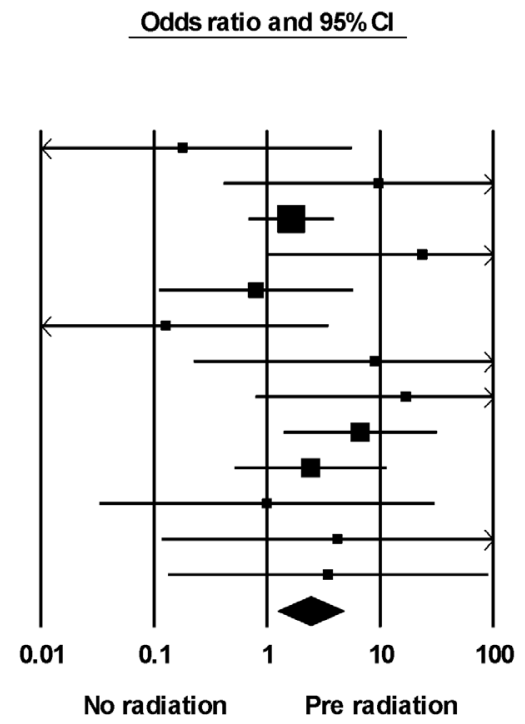

No radiation

Fig. 3. Forest plot of the fistula formation rate associated with preoperative radiation. The diamond shape indicates the summary estimate of the pooled studies. CI, confidence interval.

relationship between postoperative radiation and stricture formation.

The effect of radiation on wound healing is somewhat well known. Microvascular thrombosis by radiation can lead to impaired wound healing and increased tissue friability [34]. This vessel injury is associated with diminished smooth muscle density and fibrosis of the vessel wall $[35,36]$. Although the impaired wound healing state induced by radiation may be considered to cause fistula formation, some studies stated that there was not a significant association between radiation and fistula formation $[37,38]$. Our study verified that preoperative radiation treatment is significantly associated with fistula formation. The reason why postoperative radiation may not be associated with fistula formation is that fistula formation is a rather early complication, and the radiation effect is typically seen 3 months after completion of radiation treatment [32].

\section{LIMITATIONS AND CONCLUSION}

This study is a review study investigating the effect of perioperative radiation treatment on stricture and fistula formation in patients with hypopharyngeal reconstruction. The thorough search for the enrolled studies and robust meta-analysis strengthen this study. On the other hand, our study has several limitations. First, we could not analyze the detailed effect of radiation according to the method used because almost no studies stated the exact parameters of radiation such as the total dose, duration, etc. Therefore, this analysis can provide impor- 


\begin{tabular}{|c|c|c|c|c|c|c|}
\hline \multirow[t]{2}{*}{ Study name } & \multirow[t]{2}{*}{ Outcome } & \multicolumn{5}{|c|}{ Statistics for each study } \\
\hline & & $\begin{array}{l}\text { Odds } \\
\text { ratio }\end{array}$ & $\begin{array}{l}\text { Lower } \\
\text { limit }\end{array}$ & $\begin{array}{l}\text { Upper } \\
\text { limit }\end{array}$ & Z-Value & \\
\hline Hsueh. et al & Stricture & 1.000 & 0.030 & 33.318 & 0.000 & \\
\hline Laing. et al & Stricture & 1.500 & 0.121 & 18.540 & 0.316 & \\
\hline Ooi. et al & Stricture & 18.000 & 0.758 & 427.291 & 1.789 & \\
\hline Parmar. et al & Stricture & 3.000 & 0.084 & 107.447 & 0.602 & \\
\hline Zelken. et al & Stricture & 4.000 & 0.250 & 63.950 & 0.980 & \\
\hline Yu. et al & Stricture & 2.357 & 0.588 & 9.448 & 1.211 & \\
\hline & & 2.711 & 1.029 & 7.140 & 2.018 & \\
\hline
\end{tabular}

Heterogeneity: $\chi^{2}=2.014, \mathrm{df}=5(p=0.847) ; \mathrm{I}^{2}=00.000 \%$ Test for overall effect: $Z=2.018(p=0.044)$

Odds ratio and $95 \% \mathrm{Cl}$

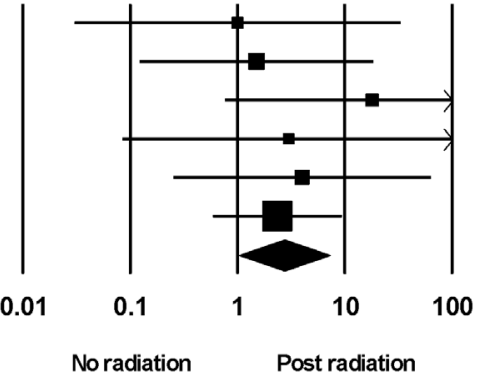

No radiation

Fig. 4. Forest plot of the stricture formation rate associated with postoperative radiation. The diamond shape indicates the summary estimate of the pooled studies. CI, confidence interval.

\begin{tabular}{|c|c|c|c|c|c|c|}
\hline \multirow[t]{2}{*}{ Study name } & \multirow[t]{2}{*}{ Outcome } & \multicolumn{5}{|c|}{ Statistics for each study } \\
\hline & & $\begin{array}{c}\text { Odds } \\
\text { ratio }\end{array}$ & $\begin{array}{l}\text { Lower } \\
\text { limit }\end{array}$ & $\begin{array}{l}\text { Upper } \\
\text { limit }\end{array}$ & Z-Value & p-Value \\
\hline Hsueh. et al & Fistula & 1.000 & 0.030 & 33.318 & 0.000 & \\
\hline Song. et al & Fistula & 0.152 & 0.004 & 5.184 & -1.047 & \\
\hline Andrades. et al & Fistula & 0.788 & 0.218 & 2.843 & -0.364 & \\
\hline Yang. et al & Fistula & 1.364 & 0.040 & 46.652 & 0.172 & \\
\hline Kim. et al & Fistula & 0.111 & 0.003 & 4.475 & -1.165 & \\
\hline Laing. et al & Fistula & 1.500 & 0.121 & 18.540 & 0.316 & \\
\hline Lee. et al & Fistula & 1.696 & 0.060 & 47.945 & 0.310 & \\
\hline Choi. et al & Fistula & 0.727 & 0.134 & 3.957 & -0.368 & \\
\hline Ooi. et al & Fistula & 0.306 & 0.012 & 7.688 & -0.720 & \\
\hline Scaglioni. et al & Fistula & 1.333 & 0.086 & 20.707 & 0.206 & \\
\hline Parmar. et al & Fistula & 1.000 & 0.034 & 29.807 & 0.000 & \\
\hline Zelken. et al & Fistula & 1.667 & 0.147 & 18.874 & 0.413 & \\
\hline & & 0.811 & 0.400 & 1.643 & -0.582 & \\
\hline
\end{tabular}

Heterogeneity: $\chi^{2}=3.339, \mathrm{df}=11(p=0.985) ; \mathrm{I}^{2}=00.000 \%$ Test for overall effect: $Z=-0.582(p=0.560)$

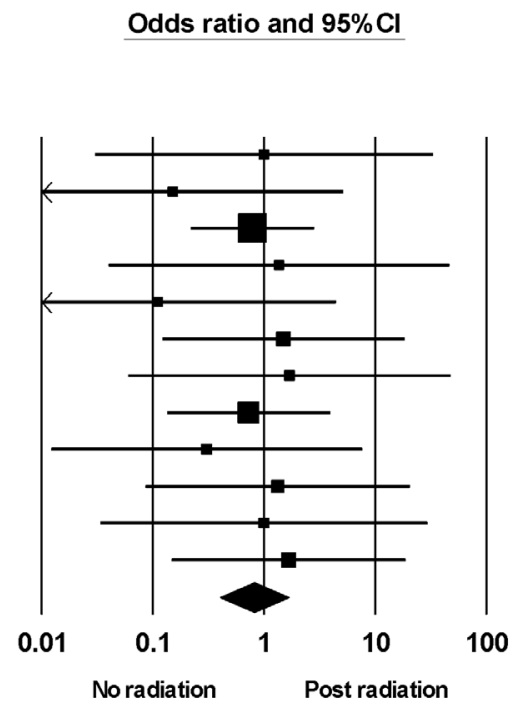

Fig. 5. Forest plot of the fistula formation rate associated with postoperative radiation. The diamond shape indicates the summary estimate of the pooled studies. CI, confidence interval.

tant indicators that support the need for further study. Second, some stated that the water-tight exquisite suture technique could prevent fistula formation [12]. However, due to the nature of the meta-analysis, we had to use extraction data from the results of many different surgeons. In addition, more randomized or prospective studies should be conducted to verify the radiation effect on postoperative complications with longterm follow-up.

In conclusion, preoperative and postoperative radiation treatment had a significant effect on the fistula and stricture formation rate at the hypopharyngeal reconstruction site. Depending on the use of perioperative radiation treatment, this study can support the surgeon's ability to predict and prevent postoperative complications.

\section{NOTES}

\section{Conflict of interest}

No potential conflict of interest relevant to this article was reported.

\section{ORCID}

Jin Yong Shin

https://orcid.org/0000-0003-2680-7411

Sun-Young Lee https://orcid.org/0000-0001-9121-0182

Si-Gyun Roh https://orcid.org/0000-0003-2865-0075

Nae-Ho Lee https://orcid.org/0000-0003-1354-8203

Author contribution

Conceptualization: SYL. Data curation: SYL. Formal analysis: 
SYL, SGR. Methodology: JYS. Project administration: JYS. Visualization: JYS, SGR, NHL. Investigation: JYS. Resources: JYS. Software: SGR, NHL. Writing - original draft: JYS. Writing - review \& editing: JYS.

\section{REFERENCES}

1. Disa JJ, Pusic AL, Hidalgo DA, Cordeiro PG. Microvascular reconstruction of the hypopharynx: defect classification, treatment algorithm, and functional outcome based on 165 consecutive cases. Plast Reconstr Surg 2003;111:652-60.

2. Suh JM, Chung CH, Chang YJ. Head and neck reconstruction using free flaps: a 30-year medical record review. Arch Craniofac Surg 2021;22:38-44.

3. Clark JR, Gilbert R, Irish J, Brown D, Neligan P, Gullane PJ. Morbidity after flap reconstruction of hypopharyngeal defects. Laryngoscope 2006;116:173-81.

4. Anthony JP, Singer MI, Deschler DG, Dougherty ET, Reed CG, Kaplan MJ. Long-term functional results after pharyngoesophageal reconstruction with the radial forearm free flap. Am J Surg 1994;168:441-5.

5. Scharpf J, Esclamado RM. Reconstruction with radial forearm flaps after ablative surgery for hypopharyngeal cancer. Head Neck 2003;25:261-6.

6. Markou KD, Vlachtsis KC, Nikolaou AC, Petridis DG, Kouloulas AI, Daniilidis IC. Incidence and predisposing factors of pharyngocutaneous fistula formation after total laryngectomy. Is there a relationship with tumor recurrence? Eur Arch Otorhinolaryngol 2004;261:61-7.

7. Choi S, Schwartz DL, Farwell DG, Austin-Seymour M, Futran $\mathrm{N}$. Radiation therapy does not impact local complication rates after free flap reconstruction for head and neck cancer. Arch Otolaryngol Head Neck Surg 2004;130:1308-12.

8. Liberati A, Altman DG, Tetzlaff J, Mulrow C, Gotzsche PC, Ioannidis JP, et al. The PRISMA statement for reporting systematic reviews and meta-analyses of studies that evaluate healthcare interventions: explanation and elaboration. BMJ 2009; 339:b2700.

9. Hsueh JH, Hsieh YH, Lin YS, Lin YS, Yang KC, Liu WC. A novel application of double-paddle peroneal chimeric flap as external sentinel monitor in hypopharyngeal reconstruction. Ann Plast Surg 2017;78(3 Suppl 2):S70-5.

10. Zhang C, Chen S, Zhu M, Chen D, Chen H, Zheng H. Combined use of gastric pull-up and pectoralis major flaps for massive defects after total laryngopharyngoesophagectomy in patients with advanced hypopharyngeal carcinoma. Eur Arch Otorhinolaryngol 2015;272:3557-64.

11. Song M, Chen SW, Zhang Q, Yang AK, Zhuang SM, Wang LP, et al. External monitoring of buried radial forearm free flaps in hypopharyngeal reconstruction. Acta Otolaryngol 2011;131: 204-9.

12. Andrades P, Pehler SF, Baranano CF, Magnuson JS, Carroll WR, Rosenthal EL. Fistula analysis after radial forearm free flap reconstruction of hypopharyngeal defects. Laryngoscope 2008;118:1157-63.

13. Zhang C, Zhu M, Chen M, Chen D, Chen S, Zheng H. Free flap combined with pectoralis major flap for reconstruction after total laryngopharyngectomy in patients with advanced hypopharyngeal carcinoma. Acta Otolaryngol 2016;136:841-6.

14. Chahine KA, Chaffanjon P, Bettega G, Lebeau J, Reyt E, Righini CA. Gastro-omental free flap in the reconstruction of the unfavourable hypopharyngeal defects: a functional assessment. J Plast Reconstr Aesthet Surg 2009;62:1367-73.

15. Amin AA, Rifaat M, Ellabban MA, Zedan M, Kamel M, Bassiouny M. Transaxillary thoracodorsal artery perforator flap: a versatile new technique for hypopharyngeal reconstruction. J Reconstr Microsurg 2014;30:397-404.

16. Yang CC, Lee JC, Wu KC, Chang SH. Voice and speech outcomes with radial forearm free flap-accompanied phonation tube after total pharyngolaryngectomy of hypopharyngeal cancer. Acta Otolaryngol 2011;131:847-51.

17. Hsiao HT, Leu YS, Chang YC, Yang JC, Tung KY. Voice and swallowing after laryngopharyngectomy and free ileocolic flap reconstruction for hypopharyngeal cancer. Ann Plast Surg 2009;62:390-4.

18. Kim SC, Kim EK. Externalized monitoring of totally buried free flap in hypopharyngeal reconstruction. J Craniofac Surg 2013;24:575-8.

19. Fujiwara T, Shih HS, Chen CC, Tay SK, Jeng SF, Kuo YR. Interdigitation of the distal anastomosis between tubed fasciocutaneous flap and cervical esophagus for stricture prevention. Laryngoscope 2011;121:289-93.

20. Laing TA, Van Dam H, Rakshit K, Dilkes M, Ghufoor K, Patel $\mathrm{H}$. Free jejunum reconstruction of upper esophageal defects. Microsurgery 2013;33:3-8.

21. Lee JC, Hsu WT, Yang CC, Chang SH. A fabricated forearm free flap with accompanying phonation tube for simultaneous reconstruction of a pharyngolaryngeal circumferential defect and voice loss: new surgical modification with functional phonation outcome. Laryngoscope 2013;123:344-9.

22. Ooi ASH, Teven CM, Inbal A, Chang DW. The utility of the musculocutaneous anterolateral thigh flap in pharyngolaryngeal reconstruction in the high-risk patient. J Surg Oncol 2017; 115:842-7.

23. Scaglioni MF, Lin TS, Chen YC, Tsai YT, Yang CH, Wu CC, et al. The free inverted omega-shaped flap for circumferential hy- 
popharyngeal reconstruction with simultaneous neck skin defect. Microsurgery 2018;38:51-9.

24. Parmar S, Al Asaadi Z, Martin T, Jennings C, Pracy P. The anterolateral fasciocutaneous thigh flap for circumferential pharyngeal defects: can it really replace the jejunum? Br J Oral Maxillofac Surg 2014;52:247-50.

25. Zelken JA, Kang CJ, Huang SF, Liao CT, Tsao CK. Refinements in flap design and inset for pharyngoesophageal reconstruction with free thigh flaps. Microsurgery 2017;37:112-8.

26. Yu P, Lewin JS, Reece GP, Robb GL. Comparison of clinical and functional outcomes and hospital costs following pharyngoesophageal reconstruction with the anterolateral thigh free flap versus the jejunal flap. Plast Reconstr Surg 2006;117:968-74.

27. Yu P, Robb GL. Pharyngoesophageal reconstruction with the anterolateral thigh flap: a clinical and functional outcomes study. Plast Reconstr Surg 2005;116:1845-55.

28. Lewin JS, Barringer DA, May AH, Gillenwater AM, Arnold $\mathrm{KA}$, Roberts DB, et al. Functional outcomes after laryngopharyngectomy with anterolateral thigh flap reconstruction. Head Neck 2006;28:142-9.

29. Nakatsuka T, Harii K, Asato H, Ebihara S, Yoshizumi T, Saikawa $\mathrm{M}$. Comparative evaluation in pharyngo-oesophageal reconstruction: radial forearm flap compared with jejunal flap: a 10-year experience. Scand J Plast Reconstr Surg Hand Surg 1998;32:307-10

30. Su CY, Chiang YC. The fabricated radial forearm flap in pharyngolaryngeal surgery: saliva leakage and its prevention. $\mathrm{Br} \mathrm{J}$ Plast Surg 1995;48:212-7.

31. Perez CA, Stanley K, Rubin P, Kramer S, Brady L, Perez-Tamayo
$\mathrm{R}$, et al. A prospective randomized study of various irradiation doses and fractionation schedules in the treatment of inoperable non-oat-cell carcinoma of the lung. Preliminary report by the Radiation Therapy Oncology Group. Cancer 1980;45:2744-53.

32. Coia LR, Myerson RJ, Tepper JE. Late effects of radiation therapy on the gastrointestinal tract. Int J Radiat Oncol Biol Phys 1995;31:1213-36.

33. Mavroidis P, Laurell G, Kraepelien T, Fernberg JO, Lind BK, Brahme A. Determination and clinical verification of dose-response parameters for esophageal stricture from head and neck radiotherapy. Acta Oncol 2003;42:865-81.

34. Kim HS, Chung CH, Chang YJ. Free-flap reconstruction in recurrent head and neck cancer: a retrospective review of 124 cases. Arch Craniofac Surg 2020;21:27-34.

35. Guelinckx PJ, Boeckx WD, Fossion E, Gruwez JA. Scanning electron microscopy of irradiated recipient blood vessels in head and neck free flaps. Plast Reconstr Surg 1984;74:217-26.

36. Erkan M, Hausmann S, Michalski CW, Schlitter AM, Fingerle AA, Dobritz M, et al. How fibrosis influences imaging and surgical decisions in pancreatic cancer. Front Physiol 2012;3:389.

37. Bengtson BP, Schusterman MA, Baldwin BJ, Miller MJ, Reece GP, Kroll SS, et al. Influence of prior radiotherapy on the development of postoperative complications and success of free tissue transfers in head and neck cancer reconstruction. Am J Surg 1993;166:326-30.

38. Kiener JL, Hoffman WY, Mathes SJ. Influence of radiotherapy on microvascular reconstruction in the head and neck region. Am J Surg 1991;162:404-7. 